\title{
Ponderações didáticas e pedagógicas sobre o uso das situações-problema no contexto da abordagem CTS
}

\author{
Didactic and pedagogical considerations on the use of problem- \\ situations in the context of the STS approach
}

\author{
Elisangela Barreto Santana ${ }^{1}$ \\ José Alexandre da Silva Valente ${ }^{2}$ \\ Nádia Magalhães da Silva Freitas ${ }^{3}$
}

\section{Resumo}

Nesta pesquisa buscamos caracterizar os processos de produção de conhecimentos que culminaram com a proposição de critérios para avaliar as situações-problema mediadoras da abordagem de ensino CTS. Temos por objetivo apontar que aspectos emergem com o uso de situações-problema no ensino de Ciências, notadamente no campo didático e pedagógico. Tal processo investigativo se deu no contexto de um Coletivo de Estudos, com professores de Ciências, configurando-se como uma pesquisa-ação, de cunho qualitativo. À luz da didática das ciências, avaliamos quatro projetos desenvolvidos com estudantes dos anos finais do ensino fundamental, a partir das manifestações dos professores, usando os critérios da Análise Textual Discursiva. Emergiram três categorias de análise, que nos dão base empírica para afirmar que as situações-problema se configuram enquanto estratégia didática e pedagógica, nos seguintes termos: as situações-problema atendem as necessidades de conteúdo, as necessidades dos estudantes e as necessidades didáticas e pedagógicas. Consideramos viáveis como recurso problematizador que introduz discussões no campo da abordagem de ensino CTS, nos anos finais do ensino fundamental.

Palavras chave: situações-problema; ensino de ciências; abordagem CTS; didática das ciências, pesquisaação.

\begin{abstract}
In this research we aimed to characterize the knowledge production processes that culminated with the proposition of criteria to evaluate the problem-situations that mediate the CTS approach. We pointed out which aspects emerge with the use of problem-situations in science education, notably in the didactic and pedagogical field. This investigative process occurred in the context of a Study Collective with Science teachers, which is configured as action research, of a qualitative nature. In the light of science didactics, we evaluated four projects developed with students of the final years of elementary school, based on teachers' manifestations, using the criteria of Discursive Textual Analysis. Three categories of analysis emerged that give us an empirical basis to state that problem-situations are configured as a didactic and pedagogical strategy, in the following terms: problem-situations meet the content needs, the students' needs and the didactic and pedagogical needs. We consider it viable as a problematizing resource that introduces discussions in the field of the CTS approach in the final years of elementary school.
\end{abstract}

Keywords.

Keywords: problem-situations; science education; CTS approach; science didactics; action research.

\footnotetext{
${ }^{1}$ Universidade Federal do Pará | elisangela.santana.bs@hotmail.com

${ }^{2}$ Universidade Federal do Pará | alexvalt@ufpa.br

3 Universidade Federal do Pará | nadiamsf@yahoo.com.br
} 


\section{Introdução}

Discussões e a busca por mudanças pedagógicas chegaram às universidades, nos cursos de licenciatura e pós-graduação, e não se pode negar que tal tendência tem transformado consideravelmente a formação de professores e a prática docente. Nesse contexto, surgem diversas alternativas de práticas, processos e recursos que trazem consigo elementos que favorecem professores da educação básica às inovações didáticas e pedagógicas (LIBÂNEO; PIMENTA, 1999; OLIVEIRA, COURELA, 2013).

A prática docente, no contexto da sala de aula, requer revisita constante às metodologias de ensino, no sentido de questionar, autoavaliar e realizar mudanças necessárias, frente às transformações sociais que têm ocorrido na sociedade. Proposições ao ensino representam, no conjunto, processo delicado e desafiador. Contudo, pesquisas educacionais têm trazido resultados que apontam ações e realizações exitosas no ensino de Ciências (NICOLA; PANIZ, 2016; MIRANDA et al, 2016, 2018).

Desse modo, entendemos a necessidade de busca por estratégias didáticas e pedagógicas que favoreçam as necessárias mudanças no ensino de Ciências. Essas, no entanto, devem estar pautadas em um referencial que valorize a formação cidadã e a alfabetização científica. Das muitas alternativas no ensino de ciências, apropriamo-nos da abordagem de ensino Ciência, Tecnologia e Sociedade (CTS), por seu compromisso com uma educação que dê subsídios aos estudantes a investigarem os objetos de conhecimento das ciências de uma maneira crítica e autônoma (SANTOS, 2012).

Outra característica da abordagem CTS, promissora ao ensino de Ciências, é a valorização que faz de recursos que mobilizem discussões das inter-relações entre ciência e tecnologia, apontando os desafios e os impactos de sua implementação na sociedade e no ambiente (CACHAPUZ et al., 2011). Recentemente, pesquisas vêm apontando uma tendência de tentativas de implementação da abordagem de ensino CTS na educação básica (FERNANDES; STRIEDER, 2017; MIRANDA et al, 2016, 2018), o que vai ao encontro de documentos educacionais norteadores, que incentivam e valorizam a elaboração de projetos de intervenções pedagógicas que criam um ambiente de construção de autonomia e de exercício da cidadania (BRASIL, 2017).

Contudo, ainda parece desafiador desenvolver estratégias que favoreçam a crianças dos anos finais do ensino fundamental a participação em atividades de ensino. Transformar a sala de aula em um ambiente educacional diferenciado exige habilidade e o uso de estratégias que mobilizem mudanças. Nesse sentido, a problematização é um passo fundamental se pretendemos fazer uso da abordagem de ensino CTS, nesse nível educacional.

A Metodologia da Problematização (MP) tem inspiração na concepção histórico-crítica da educação, influenciada fortemente pela concepção que Paulo Freire defendia - a Pedagogia Libertadora Problematizadora -, ou seja, Paulo Freire acreditava que a educação deve conduzir à conscientização e, esta, por último, resulta em ações sociais conscientes e responsáveis (BERBEL, 1999; FREIRE, 1980; 2000; VASCONSELLOS, 1999). Um recurso apropriado é o uso de situações-problema, como recurso didático e pedagógico, com o qual é possível fomentar discussões CTS (SANTANA, 2015; SANTANA; VALENTE; FREITAS, 2019). Desenvolver tais estratégias deve levar em consideração o tema abordado, o desenvolvimento cognitivo dos estudantes, ou seja, seu nível educacional, o tempo para a execução das atividades e, acima de tudo, as etapas que serão utilizadas e os objetivos a alcançar, o que representa um desafio em termos didáticos. 
Por entender essa necessidade, dispomo-nos, no presente trabalho, a fazer uma análise do uso de situações-problema no ensino de ciências, nos anos finais do ensino fundamental, como estratégia didática e pedagógica mediadora da abordagem de ensino CTS. Dessa forma, a presente pesquisa se conduziu pela seguinte questão: em que termos o uso de situações-problema contribui para o ensino de Ciências, no contexto da abordagem de ensino CTS, notadamente no que se refere aos aspectos didáticos e pedagógicos? Por sua vez, temos como objetivo apontar que aspectos emergem com o uso de situaçõesproblema no ensino de Ciências, notadamente no campo didático e pedagógico.

O artigo está organizado nas seguintes seções: introdução, na qual justificamos o trabalho, apresentamos a questão de investigação que nos orientou e o objetivo da presente pesquisa; nos caminhos metodológicos, apresentamos o cenário da pesquisa, os sujeitos participantes, o objeto de investigação e as metodologias adotadas para a coleta e a análise dos dados obtidos. Na sequência, apontamos os resultados obtidos, conforme as categorias de análise que emergiram da análise, a saber: as situações-problema atendem as necessidades de conteúdo; as situações-problema atendem as necessidades dos estudantes e as necessidades didáticas e pedagógicas dos professores. Por último, apresentamos algumas considerações que julgamos pertinentes, diante dos resultados obtidos com a pesquisa.

\section{Caminhos metodológicos}

A presente pesquisa ocorreu em uma Escola Assistencialista de um Comando Militar da região amazônica, Escola Tenente Rego Barros (ETRB), envolvendo os professores de Ciências, no âmbito de um Coletivo de Estudos. Os aspectos que abordamos permitem caracterizar a pesquisa como qualitativa (MINAYO, 2016). Segundo Thiollent (2007), as etapas que adotamos a configuram como pesquisa-ação, na qual a relação de cooperação (pesquisadores/professores) e de aprendizado (estudantes/professores/pesquisadores) estabeleceu-se.

A compreensão de Coletivo de Estudos que temos origina-se de Raposo (2017). Para a autora, essa modalidade formativa, de configuração de estudos e discussões em grupo, favorece o sentimento de igualdade dos sujeitos, o que facilita o processo reflexivo e uma abordagem multidimensional, que oportuniza aos participantes novos aprendizados. Em Imbernón (2009), temos a importância de evitar um cenário de hierarquia entre o professor formador e os professores participantes, visto que, ao se estabelecer igualdade entre os sujeitos, o ambiente de aprendizagem se torna mais propício à aprendizagem reflexiva e à autonomia, destacando-se como estratégia mobilizadora de aprendizagens ativas.

Durante os encontros formativos com os professores, houve a apreensão teórica que subsidiou as ações. Dessa forma, os professores se apropriaram da abordagem de ensino CTS, do uso de situações-problema enquanto estratégia materializadora da MP e de discussões sobre as etapas de elaboração de projetos pedagógicos.

Seguiram-se reuniões de planejamento de projetos, com o exercício da elaboração das estratégias de problematização, ou seja, preparação das situações-problema, que desencadearam as atividades de quatro projetos, apresentados e realizados com os estudantes do $6^{\circ}$ ao $9^{\circ}$ ano do ensino fundamental. Cabe destacar, que essas situaçõesproblema tinham por objetivo privilegiar o questionamento e a crítica de problemas sociais e/ou ambientais, controversos ou não; dar margem à apreensão de conhecimentos 
científicos necessários à sua elucidação e, ainda, possibilitar o exercício da cidadania, por fomentar a tomada de consciência e/ou a tomada de decisão.

Para a compreensão das atividades desenvolvidas e, com vistas ao atendimento do objetivo de pesquisa, qual seja, fazer uma análise do uso das situações problema à luz da didática das ciências, recorremos à Análise Textual Discursiva (ATD) (MORAES; GALIAZZI, 2011). Buscamos o "novo emergente", a partir do "corpus" de análise, a saber: a transcrição de entrevistas, individuais e coletivas; o diário de formação; transcrição das reuniões de planejamentos, que foram gravadas em áudio e vídeo e o uso de questionários, usado inicialmente e posteriormente, em caráter individual.

\section{Considerações iniciais}

Em busca de um referencial que mediasse nossa investigação, deparamo-nos com os autores Libâneo (1994) e Zabala (1998). E apropriamo-nos de conceitos pertinentes ao estudo da didática, os quais permearam o processo de pesquisa-ação, no contexto do Coletivo de Estudos (professores de Ciências em processo de formação continuada).

O campo da didática se estabeleceu a partir de Comenius (1966), com a apresentação da "Didática Magna", cujas principais discussões a estabeleceu enquanto teoria, definindo-a como a arte de ensinar tudo a todos. Esse conceito ainda está presente nos discursos de autores que trabalham com a didática enquanto campo de estudos (LIBÂNEO, 1994; ZABALA, 1998).

A didática é o principal ramo de estudo das áreas pedagógicas, pois é por meio dela que se investigam os fundamentos, as condições e as práticas de ensino. O autor defende ainda, que cabe à didática "[...] converter objetivos sociopolíticos e pedagógicos em objetivos de ensino, selecionar conteúdos e métodos [...], estabelecer os vínculos entre ensino e aprendizagem" (LIBÂNEO, 1994, p. 26).

Dessa forma, ao passo que discutimos os resultados alcançados, em consonância com os aspectos apresentados e defendidos por Libâneo (1994) e Zabala (1998), emergiram elementos que nos permitiram estabelecer critérios para avaliar as situações-problema mediadoras da abordagem de ensino CTS à luz da didática. Interessamo-nos em saber se as situações-problema atendem as necessidades de conteúdo, as necessidades dos estudantes e as necessidades didáticas e pedagógicas.

\section{As situações-problema atendem as necessidades de conteúdo}

Por necessidade de conteúdo, entendemos que uma educação, seja por meio da abordagem CTS ou outra, precisa estar comprometida com os objetos de conhecimento, atualmente organizadas em unidades temáticas, conforme proposições da Base Nacional Comum Curricular (BNCC) (BRASIL, 2017). Embora desafiadora, a educação deve estar comprometida em proporcionar aos estudantes o conhecimento científico necessário para que avancem na escolaridade e estejam aptos a se inserirem na sociedade. Assim, buscamos identificar, no contexto das situações-problema, vinculados aos projetos de ensino, se tal necessidade foi contemplada. Para tal, recorremos aos professores que nos relataram:

No caso do projeto "Reconhecendo a biodiversidade", como é voltado para o sétimo ano, são seres vivos de uma maneira geral, aí cai temas transversais, queira ou não esbarram em outras questões, as questões 
sociais, as questões econômicas. Por que não se preserva tanto quanto se gostaria? Por que os países que mais poluem são os que menos querem ajudar? E aí, inevitavelmente vai tocar em outras questões, nos conteúdos de sala de aula (Claudineia, entrevista);

Hoje, mais uma vez reafirmei em mim a necessidade do conteúdo científico como base para haver competência para se refletir, argumentar, criticar, opinar onde as situações de ciência e tecnologia se fizerem presentes (Joacelma, diário de formação);

A temática escolhida foi lixo espacial e os conteúdos abordados foram relativos a conceitos básicos de Astronomia pretendidos para o $6^{\circ}$ ano (estrelas, galáxias, constelações, sistema solar, fases da lua, eclipses ...) (Nelba, entrevista).

Os professores sempre se preocupavam, durante o planejamento dos projetos, em identificar quais os objetos de conhecimento que seriam abordados. Em reunião de planejamento, sobre a produção de um projeto sobre Espaços Naturais, a preocupação dos professores com os conteúdos era evidente, pois os mesmos nos dizem:

O projeto "Espaços Naturais" é para trabalhar educação ambiental [...] daí ter um minhocário, vamos trabalhar anelídeos, levamos lá (Barbiere, reunião de planejamento). [...] os conteúdos que podem ser explorados: $6^{\circ}$ ano - solo, recursos naturais - água (Nelba, reunião de planejamento). [...] no sétimo ano - alimentação saudável, nutrição. No oitavo ano vai tratar de ambientes naturais em espaços urbanos (Joacelma, reunião de planejamento);

As discussões sobre os projetos didáticos foram muito produtivas para a construção de um projeto que já havíamos iniciado, intitulado de "Espaço Natural", que pretendemos aplicar do $6^{\circ}$ ano ao $8^{\circ}$ ano, em ações variadas que perpassam por vários assuntos do currículo, mas que agora, com as discussões CTS, está tomando uma forma mais direcionada para essa abordagem (Cícera, diário de formação).

De acordo com Zabala (2010, p. 41), esses conteúdos podem ser fatuais ou conceituais - os conteúdos fatuais dizem respeito ao "[...] conhecimento de fatos, acontecimentos, situações, dados e fenômenos". Todos esses conteúdos ou objetos de conhecimento devem estar presentes e ser preocupação dos professores de Ciências. Assim, o que faz uma estratégia de ensino eficaz é se ela atende a necessidade de tornar o estudante capaz de usar o objeto de conhecimento para interpretar, compreender e explicar um fenômeno ou acontecimento, ao invés de apenas repetir ou reproduzir conceitos, como mero exercício de fixação de conteúdos (ZABALA, 2010).

Outra característica importante é o aprendizado dos conteúdos procedimentais, que a BNCC interpreta como habilidades que os estudantes precisam desenvolver para realizar tarefas e associá-las ao seu dia a dia (BRASIL, 2017; ZABALA, 2010). A esse respeito, evidenciamos as habilidades que foram mobilizadas, como podemos atestar na fala dos professores:

Agora eu estou na expectativa, por que hoje eles vão entregar os vídeos que produziram sobre o lixo espacial, então eu estou super animado (Alamar, reunião de planejamento); 
E até a questão de como orientar eles, de como é que monta um trabalho científico, adaptando à idade deles e eles expõem. $\bigcirc$ trabalho escrito que a gente recebe, corrige e acaba incentivando eles (Cícera, entrevista).

Fazia parte do planejamento e das ações dos professores desenvolver os conteúdos procedimentais; por isso, em seu planejamento incluíam estímulo à produção de vídeos e outras ações que envolvessem os estudantes no exercício das suas habilidades, que os permitissem realizar tarefas. Para Zabala (2010), tais conteúdos se referem a um conjunto de ações que têm como finalidade a realização de um objetivo e que podem envolver regras, técnicas, métodos ou o desenvolvimento de habilidades para que uma tarefa seja executada ou realizada.

Nesse sentido, os professores sempre se mostraram preocupados e suas ações convergiram sempre para a consolidação desses objetivos. Reforçando tal aspecto, o professor Barbieri ainda nos diz:

Promover atividades que envolvam o tema trabalhado em sala, mas na perspectiva de identificação de problemas sociais e ambientais pelos alunos [...] uma atividade prática é a confecção de maquetes pelos alunos, mas ao invés de uso de materiais tradicionais como isopor e outros, a reutilização de materiais alternativos disponíveis em casa, que poderiam acabar no lixo, se transformam em atividades e respostas pelos mesmos. Nesse caso, discutem-se ciências, questões socioambientais relacionadas ao lixo e também a atual economia global, pois também gera reflexão sobre economia de materiais (Barbieri, diário de formação).

A preocupação com a atitude dos estudantes também deve estar presente em uma estratégia de ensino que vise à apropriação de conhecimentos científicos. Temos assim, os seguintes relatos dos professores:

O que eu acho mais legal [...] é ver a motivação dos alunos e perceber mudança de valores neles, de atitude. Isso é muito forte neles e às vezes até mesmo nos pais. Já teve caso de pais que vieram e disseram: - Poxa! [...] ele mudou lá em casa, não deixa mais luz acesa (Nelba, reunião de planejamento);

Muda a postura e isso dá uma satisfação na gente quanto orientador. Saber que você contribuiu pra uma mudança de atitude [...] (Cícera, reunião de planejamento);

Refleti muito em como realizar uma prática pedagógica que forme pessoas preocupadas e comprometidas com o social, vivendo num mundo capitalista. Até que ponto a escola consegue influenciar na formação de personalidades com a justiça social? Ao longo de meus anos de trabalho como professora, busquei estimular discussões acerca das questões sociais envolvidas com os conteúdos científicos e tecnológicos abordados nas aulas e por diversas vezes desenvolvi estratégias para que os alunos realizassem atividades solidárias (Joacelma, diário de formação);

É preciso proporcionar ações pedagógicas que estimulem no aluno a percepção dos problemas sociais existentes, tentando formar cidadãos 
que busquem atuar na justiça social, utilizando o conhecimento científico e tecnológico desenvolvido (Joacelma, diário de formação).

Os professores destacam aqui o que Zabala (2010) denomina de conteúdos atitudinais. Para o autor, isso engloba uma série de conteúdos, a saber: valores, atitudes e normas. Os valores são princípios ou ideias éticas que nos permitem fazer juízo sobre condutas, escolhas e ações. São esses valores que possibilitam aos estudantes o exercício da cidadania, em uma atmosfera de solidariedade, respeito e responsabilidade.

Os valores desenvolvidos durante o período de escolaridade, como respeito pelos colegas, capacidade de desenvolver atividades coletivas, sentimento de coletividade, coerência entre palavras e ações, são listadas por Libâneo (1994), como atitudes que darão aos estudantes condições de continuarem aprendendo durante toda a vida, e não somente no período escolar. Esse exercício foi observado pelos professores com o uso das situaçõesproblema.

\section{As situações-problema atendem as necessidades dos estudantes}

É importante levar em consideração se uma estratégia de ensino atende as necessidades dos estudantes. Essas vão se expressar em termos do que eles podem realizar, do significado que dão ao que estão aprendendo - encontrar sentido na aprendizagem e em quanto podem se desenvolver - e potencializar a autonomia dos estudantes. Quanto a esses aspectos, os professores novamente demonstraram a devida atenção:

[...] os desafios surgem do começo ao fim, pois é muito mais fácil apenas repassarmos o máximo de informações e conhecimentos prontos e acabados aos estudantes. Entretanto, os ganhos no processo de ensino e aprendizagem foram significativos, inicialmente motivando os estudantes e atiçando ainda mais a curiosidade natural deles, porém não ofereceu respostas prontas que sanassem tais curiosidades, mas possibilitou condições para que os mesmos as buscassem, e assim, consequentemente, novos conhecimentos foram apreendidos, uma vez que os mesmos foram necessários para a elaboração das reflexões e argumentos desses estudantes (Nelba, questionário).

O processo de ensino e de aprendizagem precisa conduzir os estudantes a novas aprendizagens e desafios. Entendemos que as atividades desenvolvidas (a partir das situações-problema) não teriam relevância se não os fizessem avançar em termos de conhecimento, desenvolvimento de competências e tomada de decisão, como orienta Zabala (2010). Para isso, é necessário que os professores estabeleçam objetivos de aprendizagem que estejam ao alcance dos estudantes, levando em consideração o nível de escolaridade e o desenvolvimento cognitivo; pois, do contrário, experiências negativas e frustradas poderiam desencorajar os estudantes a novos desafios.

Quanto à preocupação em dar sentido ao aprendizado, encontramos os seguintes comentários das professoras:

Uma mãe veio nos relatar o quanto o projeto [com mediações das situações-problema] mudou sua filha [...] a filha mudou, o íntimo dela em querer ajudar o próximo. Isso vai pra vida toda, é o tipo de retorno que a gente tem (Claudineia, entrevista); 
Muitos acham que a criança e adolescente é insensível à responsabilidade social, mas é o contrário. [...] é essa fase que eles estão abertos, que eles estão mais sensíveis. É por que ninguém direciona pra isso, aí o que acontece? A escola fica só naquela coisa entediante, aí eles não querem estudar (Nelba, entrevista);

Repensamos as didáticas de ensino dos conteúdos escolares e os resultados obtidos [...] e refleti sobre a importância das discussões em grupo para que a aprendizagem aconteça. Lembramos de uma turma da escola que em aulas expositivas eles não rendia nada, se mostravam totalmente impacientes e desinteressados, porém quando esta ocorre de maneira mais dinâmica, em que eles necessitam discutir o conteúdo problematizado, produzir material, tornam-se completamente interessados e verifica-se que o conhecimento se constrói (Nelba, diário de formação).

Depreendemos que a professora Nelba reconhece o quanto uma educação que dá sentido motiva e transforma o processo de ensino e de aprendizagem. Entendemos, portanto, que as mediações propiciadas pelas situações-problema constituíram-se instrumento de fomento às discussões e à aprendizagem.

Assim, e de acordo com Zabala (2010), para que estudantes percebam que seu aprendizado tem algum sentido ou valor prático, é necessário que eles conheçam as atividades que irão desenvolver, o motivo pelos quais o tema é abordado, e quais objetivos se pretende alcançar com os mesmos. Quanto a esses aspectos, a problematização por meio de situações-problema os contempla, uma vez que parte de um problema real que tem relação com seu cotidiano, o que torna o aprendizado mais significativo para os estudantes.

Outra característica necessária a uma estratégia de ensino é que ela potencialize a autonomia dos estudantes e a possibilidade de aprendizagem. Quanto a esse ponto, temos as ponderações dos professores nos seguintes relatos:

O objetivo desse estudo [situações-problema - abordagem CTS] é preparar o aluno para o exercício da cidadania, caracterizado por uma abordagem dos conteúdos científicos no contexto social. Preparar o cidadão em ciências e tecnologia é necessário nos dias de hoje, disponibilizando representações que levem o cidadão a agir e tomar decisão, compreendendo o que está em discurso (Cícera, diário de formação);

Na elaboração das situações-problema, o passo inicial foi que essas, fossem uma estratégia pedagógica que colocasse o aluno como protagonista no seu processo de aprendizagem. Partindo desse objetivo, foram elaboradas situações-problema que tivessem relação com a vida dos estudantes participantes e que os mobilizassem para apropriação de novos conhecimentos na busca de respostas para tais questões (Nelba, questionário).

Novamente percebemos a preocupação dos professores com o processo de ensino e de aprendizagem, não com enfoque em uma formação propedêutica, mas sim com uma formação cidadã. E, para alcançar esse objetivo, a autonomia é uma qualidade primordial, pois é por meio dela que os estudantes vão poder atuar de maneira adequada. 
Zabala (2010) compreende a necessidade de professores e de estudantes assumirem uma postura de responsabilidade, que são distintas, mas complementares. Inicialmente, a intervenção do professor será maior, mas ao passo que os estudantes ganham experiência e autonomia, o engajamento dos estudantes será cada vez maior e mais significativo. As professoras expressam, de maneira geral, essa transformação quanto do envolvimento dos estudantes nos eventos de aprendizagem, a saber:

Eles divulgam na escola, eles vão na sala dos professores, eles vão na sala dos diretores, expõem os trabalhos, solicitam ajuda nas campanhas, explicam, argumentam a necessidade de ajudar naquela campanha (Joacelma, entrevista);

Conseguem cabelo para os escalpelados, fazem armadilha para mosquito (Nelba, entrevista).

Esses excertos nos fazem pensar que o uso de situações-problema, no contexto da abordagem de ensino CTS, contribui para que o ensino de Ciências seja significativo para os estudantes, atendendo suas necessidades de um aprendizado que faça sentido e os prepare para a vida.

\section{As situações-problema atendem as necessidades didáticas e pedagógicas do professor}

Elencamos aqui três critérios que devem direcionar uma estratégia pedagógica, no sentido de facilitar o processo de ensino e de aprendizagem. Assim, embora já tenha sido considerada em análise anterior, é objetivo da atividade pedagógica do professor assegurar aos estudantes o domínio dos conteúdos científicos (LIBÂNEO, 1994).

Então, avaliamos como pertinente incluir nessa categoria tal aspecto, considerando que o professor tem por responsabilidade fundamental o próprio domínio teórico disciplinar, pois requer em seu planejamento que ele tenha a capacidade de elaborar estratégia visando atingir os objetos de conhecimento adequados e ao nível de compreensão dos estudantes e conforme especificado no currículo escolar adotado (LIBÂNEO, 1994). Ao considerarmos nossa vivência junto aos professores, especificamente no que diz respeito à elaboração das situações-problema e às discussões realizadas na abordagem de determinada temática, podemos afirmar que eles são portadores de um amplo repertório de conhecimentos relativos às ciências, o que nos leva a ponderar que apresentam domínio teórico.

Outra característica importante em uma estratégia de ensino é que ela crie condições e meios de aprendizagem aos estudantes. Notamos essa preocupação nos professores, conforme os relatos que se seguem:

Eu acredito assim, à medida que você usa uma metodologia [uso das situações-problema], sistematiza o trabalho, você tem um objetivo [...] e um ano depois aquele objetivo aumenta mais alguma coisa, sempre tem o que aprimorar de um ano para o outro e o retorno dos alunos é maravilhoso, mas do que se a gente ficasse só na sala de aula (aula tradicional) (Claudineia, entrevista); 
A ação de problematização consistiu na exibição de um vídeo sobre a temática [lixo espacial] e, posteriormente, situações-problema foram lançadas. Quanto aos resultados obtidos, de imediato, se percebeu uma empolgação nos estudantes e o potencial dessa estratégia metodológica para emergir opiniões e discussões e para o favorecimento da aprendizagem de conceitos científicos de difícil compreensão (Nelba, questionário).

Entendemos que as ações desenvolvidas pelos professores representaram atividades de mediação, as quais forneceram os meios e as condições para tornar o estudante um sujeito ativo no processo de ensino e de aprendizagem, nos termos de Libâneo (1994).

Um aspecto ainda importante a avaliar é se a estratégia contribuía para orientar o estudante para a formação cidadã. Nesse respeito, encontramos os seguintes relatos dos professores:

Essa proposta pedagógica [uso de situações-problema] contemplou aspectos da abordagem CTS, uma vez que problematizou questões CTS, estas, reais e relacionadas à vida dos estudantes/sociedade, e possibilitou condições para o desenvolvimento de habilidades necessárias para solução destas situações-problema propostas, consonante com os objetivos da educação cidadã crítica. Acredito ainda, que o principal desdobramento foi o envolvimento social, o qual os estudantes demonstraram, reverberando em conscientes tomadas de decisão (Nelba, questionário inicial).

A professora Nelba avalia que a problematização gera no estudante a necessidade de apreensão de novos conhecimentos. Uma boa situação-problema instiga o estudante a se distanciar criticamente do conhecimento que já possui, rumo à apreensão de novos e desafiantes conhecimentos. Deve ainda favorecer a aprendizagem de conhecimentos científicos que façam sentido na sua vida, além de propiciar o desenvolvimento de habilidades que tenham relação com sua realidade (FRANCISCO JÚNIOR, 2010). A professora Joacelma ainda completa:

Refleti nesse dia que o ensino de ciências em uma abordagem CTS deve ser uma alfabetização científica, preocupada com a formação de pessoas capazes de analisar fatos em seu dia a dia e serem capazes de agir para proporcionar o crescimento social. Essas discussões me remeteram a minha vida profissional no Colégio Salesiano Nossa Senhora do Carmo, em que na filosofia de Dom Bosco, fundador da congregação Salesiana, busca formar cidadãos preocupados com as questões sociais, por isto fazíamos muitas interações com a comunidade, principalmente da área mais pobre, próxima da escola. O estímulo à democracia e aos valores humanos também são características de uma abordagem CTS. Novamente a Escola Salesiana me veio à mente, onde o estímulo à formação de pessoas justas e valores como a solidariedade, fraternidade, respeito ao próximo e generosidade também são inseridos na filosofia de D. Bosco. Durante as discussões, fui fazendo uma análise em minhas práticas pedagógicas e percebi que estou no caminho para o ensino numa abordagem CTS [...] mas com um longo caminho a percorrer para chegar o mais próximo da qualidade do ensino nessa abordagem (Joacelma, diário de formação). 
O favorecimento da formação cidadã parece ter sido contemplado na ação dos professores. A professora reconhece a necessidade da alfabetização científica para que os estudantes demonstrem atitudes que refletem responsabilidade social e solidariedade, aspectos estes emergentes na abordagem de ensino CTS (TENEIRO-VIEIRA; VIEIRA, 2014).

Em síntese, podemos depreender, dos aspectos acima analisados, que nas situaçõesproblema emergiram critérios que julgamos necessários para a sua implementação no contexto da abordagem CTS (QUADRO 1), a saber:

(1) atendeu às necessidades de conteúdo, dos quais destacamos os conteúdos fatuais, conceituais, atitudinais e procedimentais, pressupondo o domínio amplo do conhecimento;

(2) atendeu às necessidades dos estudantes, quanto ao sentido dado à aprendizagem, de modo que potencializou sua autonomia e;

(3) atendeu às necessidades pedagógicas, na medida em que se criou condições e meios de aprendizagem, inclusive para a formação cidadã.

Quadro 1: aspectos didáticos e pedagógicos das situações-problema no ensino de Ciências

\begin{tabular}{|c|l|}
\hline $\begin{array}{c}\text { Critérios para a análise da proposta didático-pedagógica (uso de situações-problema, } \\
\text { mediada pela abordagem de ensino CTS) }\end{array}$ \\
\hline \multirow{2}{*}{$\begin{array}{c}\text { Atende as } \\
\text { necessidades } \\
\text { de conteúdo }\end{array}$} & Fatuais \\
\cline { 2 - 2 } & Conceituais \\
\cline { 2 - 2 } $\begin{array}{c}\text { Atende as } \\
\text { necessidades } \\
\text { dos estudantes }\end{array}$ & Atitudinais \\
\cline { 2 - 2 } Atende as & Confedimentais \\
\cline { 2 - 2 } $\begin{array}{c}\text { necessidades } \\
\text { pedagógicas }\end{array}$ & $\begin{array}{l}\text { Assegura aos estudantes o aprendizado domínio dos } \\
\text { conteúdos científicos, mediante domínio teórico } \\
\text { disciplinar do professor }\end{array}$ \\
\cline { 2 - 2 } & Cria condições e meios de aprendizagem \\
\cline { 2 - 2 } & Orienta para a formação cidadã \\
\hline
\end{tabular}

Fonte: os autores

\section{Considerações finais}

Nossa compreensão das situações-problema foi aprimorada, na medida em que os projetos pedagógicos foram desenvolvidos na escola. Em reuniões de planejamento com os professores, a cada novo projeto, tínhamos a oportunidade de avaliar as estratégias adotadas (inclusive as situações-problema) e os resultados obtidos. Assim, refletimos aqui sobre a questão de investigação que nos mobilizou, a saber: "em que termos o uso de situações-problema contribui para o ensino de Ciências, no contexto da abordagem de ensino CTS?" Em relação ao objetivo elencado, temos: ponderar sobre os aspectos que emergem com o uso de situações-problema no ensino de ciências, notadamente no campo didático e pedagógico.

A importância dessa pesquisa parece residir na compreensão do uso das situaçõesproblema enquanto estratégia didática e pedagógica. Nesse sentido, cabe apresentar algumas considerações, que, em nossa análise, são necessárias. Inicialmente, compreendemos a preocupação dos professores, em geral, com o aprendizado dos 
estudantes. Isso porque, na educação básica, a abordagem dos objetos de conhecimento que os associe ao contexto social e ambiental parece insuficiente, resultando em pouca valorização, por parte dos estudantes, ao que estão aprendendo, ou seja, ausência de sentido aos conhecimentos que Ihes são apresentados, e isto é materializado no pouco interesse que demonstram em sala de aula.

O processo de aprendizagem, vinculado a um ensino teórico e memorístico, tem se mostrado pouco eficaz; daí a necessidade de avaliar o ambiente escolar, as condutas e os processos de aprendizagem. Assim sendo, o estudo dos aspectos didáticos se mostra providencial, uma vez que contribui para o aperfeiçoamento da aprendizagem ampla dos conteúdos, ou seja, no que diz respeito aos conteúdos fatuais, conceituais, atitudinais e procedimentais.

Há ainda um aspecto a considerar, a legitimação que a ciência dá às pesquisas educacionais. O cientificismo positivista credita às pesquisas o caminho que conduzirá ao sucesso educacional, notadamente no uso de "novos métodos e técnicas", sem considerar que as experiências de vida e de sala de aula do professor são os aspectos motivacionais mais relevantes na busca por mudanças e inovações. Considerar estratégias de ensino sem levar em consideração as demandas dos professores e da escola está em desacordo com uma proposta democrática de ensino, visto que são os professores que detêm a experiência necessária para a ressignificação do processo de ensino e de aprendizagem.

Deve partir de suas inquietações a elaboração de propostas e estratégias a serem implementadas em sala de aula, ou seja, qualquer experiência que se propõe exitosa deve levar em conta os professores e suas preocupações diante dos desafios que enfrentam em seu dia a dia. Desse ponto de vista, convém afirmar que é na mão dos professores que reside a solução (quando as condições materiais são satisfeitas, entre outras) e não o problema, referente ao processo de ensino e de aprendizagem. Assim, qualquer alternativa, oriunda de pesquisas acadêmicas ou políticas públicas, deve, antes de qualquer coisa, ouvir e considerar os aspectos que os professores julgam necessários e eficientes em termos didáticos e pedagógicos.

Nesses termos, a presente pesquisa nos possibilitou ponderar que há potencial a ser explorado no uso de situações-problema no ensino Ciências. Afirmamos ainda que os desafios à implementação da abordagem de ensino CTS na educação básica (anos finais do ensino fundamental) não devem ser considerados intransponíveis, visto que a estratégia aqui desenvolvida nos permitiu, em conjunto com os professores de ciências, elaborar, experimentar e consolidar critérios que julgamos serem suficientes para justificar seu uso enquanto estratégia didática e pedagógica. 


\section{Referências}

BERBEL, N. A. N. A Metodologia da Problematização e os ensinamentos de Paulo Freire: uma relação mais que perfeita. In: BERBEL, N. A. N (Org.). Metodologia da problematização - fundamentos e aplicações. Londrina: Ed. UEL, 1999. p. 1-28

BERBEL, N. A. N. A Problematização e a Aprendizagem Baseada em Problemas: diferentes termos ou diferentes caminhos? Interface-Comunicação, Saúde, Educação, Botucatu, v. 2, n. 2, p.139-154, 1998.

BORDENAVE, J. D.; PEREIRA, A. M. Estratégias de ensino aprendizagem. 33. ed. RJ/Petrópolis: Vozes, 2015.

BRASIL. Base Nacional Comum Curricular. Brasília: DF, 2017. Disponível em: $<$ http://basenacionalcomum.mec.gov.br/images/BNCC_El_EF_110518_versaofinal_site.pdf>. Acesso em 16 jul. 2018.

COMENIUS, J. A. Didática Magna: tratado da arte universal de ensinar tudo a todos. Lisboa: Calouste Gulbenkian, 1966.

FRANCISCO JÚNIOR, W. E. Analogias e situações problematizadoras em aulas de ciências. São Carlos: Pedro \& João Editores, 2010.

FERNANDES; R. F., STRIEDER, R. B. Dificuldades enfrentadas por professores na implementação de propostas CTS. XI Encontro Nacional de Pesquisa em Educação em Ciências - XI ENPEC. Universidade Federal de Santa Catarina, Florianópolis, SC - 3 a 6 de julho de 2017. In: Anais eletrônicos ... p. 1-9, 2017.

IMBERNÓN, F. Formação permanente do professorado: novas tendências. São Paulo: Cortez, 2009.

LIBÂNEO, J. C. Didática. $2^{a}$ ed. São Paulo: Cortez, 2013.

LIBÂNEO, J. C., PIMENTA, S. G. Formação de profissionais da educação: visão crítica e perspectiva de mudança. Educação \& Sociedade, Campinas, ano XX, n. 68, p. 239-277, 1999

MINAYO, M. C. de. S. Trabalho de campo: contexto de observação, interação e descoberta. In: MINAYO, M. C. de. S. (Org.) Pesquisa social: teoria, método e criatividade. Petrópolis, RJ: Vozes, 2016. p. 56-71. (Série Manuais Acadêmicos).

MIRANDA, N. T. G. P., BELÉM, C. G. A. O.; ANJOS, C. R., BARBIERI JÚNIOR, D.; RODRIGUES, J. M. S.; SANTANA, E. B. A abordagem CTS no ensino de ciências: o combate ao Aedes Aegypti. Revista da SBEnBio, Santa Catarina, n. 9, p. 5785-5796, 2016.

MIRANDA, N. T. G. P., BELÉM, C. G. A. O.; BARBIERI JÚNIOR, D.; RODRIGUES, J. M. S.; SANTANA, E. B. O lixo eletrônico com enfoque em discussões CTS. VI Encontro Nacional de Ensino de Biologia/ENEBIO. In: Anais eletrônicos ... Belém/PA, p. 1-12, 2018.

NICOLA, J. A., PANIZ, C. M. A importância da utilização de diferentes recursos didáticos no ensino de biologia. InFor, Inovação e Formação - Revista do Núcleo de Educação a Distância da Unesp. São Paulo/SP, v. 2, n. 1, p. 355-381, 2017.

OLIVEIRA, I.; COURELA, C. Mudança e inovação em educação: o compromisso dos professores. Interracções, Santarém, Portugal, n. 27, p. 97-117, 2013. 
OLIVEIRA, M. M. Como fazer pesquisa qualitativa. 5. ed. Petrópolis, RJ: Vozes, 2013.

RAPOSO, E. O. Coletivo de estudos, formação e práticas: itinerários de uma formação em educação para o desenvolvimento sustentável. 118 f. 2017. (Tese de Doutorado). Universidade Federal do Pará, 2017.

SANTANA. E. B.; VALENTE, J. A. S.; FREITAS, N. M. S. Metodologia da problematização: o uso de situações-problema no ensino de Astronomia. Revista Exitus, Santarém/PA, v. 9, n. 1, p. 175-201, 2019.

SNOW, C. E.; DIBNER, K. A. Science Literacy: concepts, contexts, and consequences. Washington, DC: National Academy of Sciences, 2016. Disponível em: <https://www.nap.edu/read/23595/chapter/1>. Acesso em: 13 dez. 2018.

TENREIRO-VIEIRA, C; VIEIRA, R. M. Construindo práticas didático-pedagógicas promotoras da literacia científica e do pensamento crítico. Madrid: OEI - Organização dos Estados Ibero-americanos; Iberciencia, 2014. Disponível em: <https://doczz.com.br/doc/280510/construindo-pr\%C3\%A1ticas-did\%C3\%A1ticopedag\%C3\%B3gicas-promotoras> Acesso em: 15 dez. 2018.

TENREIRO-VIEIRA, C.; VIEIRA, R. M. Literacia e pensamento crítico: um referencial para a educação em ciências e em matemática. Revista Brasileira de Educação, Rio de Janeiro, v. 18 n. 52, p. 163-248, 2013.

THIOLLENT, M. Metodologia da pesquisa-ação. 15 ed. São Paulo: Cortez, 2007.

VIEIRA, R. M.; TENREIRO-VIEIRA, C.; MARTINS, I. P. Critical thinking: conceptual clarification and its importance in science education. Science Education International, Turkey, v. 22, n. 1, p. 43-54, 2011. Disponível em: <https://files.eric.ed.gov/fulltext/EJ941655.pdf>. Acesso em: 10 dez. 2018.

ZABALA, A. A prática educativa: como ensinar. Trad.: Emani F. da F. Rosa. Porto Alegre: Artmed, 2010. 